\title{
Hibridación republicana. El bicentenario y la cultura política peruana en los siglos XIX y XXI
}

\author{
Republican hybridization: the bicentennial and Peruvian political culture \\ in the $19^{\text {th }}$ and $21^{\text {st }}$ centuries
}

Daniel Parodi Revoredo

Universidad de Lima

\section{RESUMEN}

El presente ensayo trata del republicanismo peruano y compara dos de sus periodos más emblemáticos: el que abarca el largo primer militarismo, que podemos situar entre 1822 y 1872, durante el siglo xIx, y la alternancia democrático-autoritaria que abarca el periodo 19802016, siglos xx y xxı. Aplicando el método comparativo, este trabajo intenta establecer la presencia de formas políticas reñidas con el republicanismo, como el patrimonialismo, el clientelismo y el caudillismo en ambos periodos de estudio, la que obtiene por resultado un sistema político disfuncional e hibridado ad portas de conmemorarse el bicentenario de la Independencia.

Palabras clave:

historia de la República del Perú, republicanismo, democracia, caudillismo, clientelismo, patrimonialismo, corporativismo

\section{ABSTRACT}

This essay deals with Peruvian republicanism and compares two of its most emblematic periods: the one that encompasses the long First Militarism, which can be placed in the 19th century between 1822 and 1872, and the democratic-authoritarian alternation in the 20th and $21^{\text {st }}$ centuries, that covers the period between 1980 and 2016. Using the comparative method, this research aims to establish the presence of political systems opposed to republicanism, such as patrimonialism, clientelism and caudillismo, in both periods of study, which results in a dysfunctional and hybridized political system close to commemorating the bicentennial of the independence of Peru.

Keywords:

History of the Republic of Peru, republicanism, democracy, caudillismo, clientelism, patrimonialism, corporatism 
A $d$ portas del bicentenario, son pocos los investigadores que buscan responderse la pregunta de hasta qué punto somos ya la República liberal que proyectaron los padres fundadores de la Independencia. De hecho, hace no mucho, Hugo Neira ensayó una respuesta en ¿Qué es República? (2013), cuyas primeras páginas sostienen que nuestra fragilidad e incertidumbre institucionales responden a que apenas expulsados los españoles, olvidamos preguntarnos qué tipo de república queríamos ser, pues pensábamos que los franceses, y antes los norteamericanos, habían resuelto ya una discusión que entonces nos pareció demasiado teórica.

De acuerdo con Neira, una suerte de flojera intelectual impidió que nos detuviésemos a pensar las costumbres en las que las leyes deben sustentarse. En consecuencia, del complicado divorcio entre ambas - la ley y la costumbre - resultan prácticamente todas las etapas de la historia republicana del Perú: la anarquía y posterior centralización de los tiempos de los caudillos militares; y el primer y frustrado intento de fundar una República con base en el constitucionalismo y la educación de Manuel Pardo y el Partido Civil, desde 1872. Prosigue nuestra primera república censitaria, la única que en la práctica funcionó como tal, que hemos, sin embargo, ninguneado bajo el sambenito de aristocrática (18951919). Su contrario es el largo Oncenio de Leguía, que dotó al Perú, y a buena parte de sus vecinos, de un modelo autoritario con el cual frenar la irrupción de las masas en la política, hasta bien avanzada la segunda mitad del siglo xx.

Luego se advino el APRA, cuyo cercamiento por parte de la oligarquía y el Ejército no le impidió sacar adelante la primera constitución moderna de la historia del Perú en 1979, la que cedió el paso a la también vilipendiada "década perdida" — los años ochenta—, aunque, paradójicamente, fue la única en la que vivimos una auténtica república democrática. Durante su vigencia, la población se conectó con el Estado a través de partidos y el espectro político presentó su clásica división en tres partes: derecha, centro e izquierda.

Debido a la crisis económica, a la destrucción ocasionada por el terrorismo y a las urgentes demandas sociales del Perú postransición demográfica, la Primera República Democrática' (1980-1992) implosionó en dos actos: el triunfo del outsider Alberto Fujimori en
1990 y el autogolpe perpetrado por él mismo dos años después, el 5 de abril de 1992. Luego, iniciamos un proceso de regresión republicana o de construcción/ consolidación de una nueva cultura política basada en conjugar elementos de la república inicial con aportes contemporáneos de la era global y de las tecnologías de la información y las comunicaciones (TIC).

De allí que la tesis central de este ensayo propone que, más allá de la auténtica inspiración republicana de los padres fundadores de la Independencia, hasta el día de hoy, el Perú no ha ingresado en un proceso sostenido de maduración institucional, a pesar de que la transición demográfica y la expansión estatal han permitido que una gran mayoría de peruanos comparta una serie de elementos comunes que se corresponde con la definición de nación de algunos autores clásicos, como Eric Hobsbawm (1991) y Benedict Anderson (1997).

En suma, lo que ofrecemos en las líneas siguientes es un espacio para reflexionar acerca de lo que es y lo que ha sido el casi bicentenario proyecto republicano que hace 196 y 192 años fundaran José de San Martín y Simón Bolívar, respectivamente. Compleja república, sin duda, aquella que doscientos años después sigue discutiendo la fecha de su institución.

Asimismo, advertimos al lector que este ensayo centrará su análisis en las formas políticas republicanas en los siglos XIX y XXI haciendo uso del método comparativo. De esta manera, el presente trabajo adelanta los primeros resultados de una investigación de mayor aliento en la que nos proponemos ofrecer un tomo completo de reflexión sobre el Perú republicano, a la luz del bicentenario de la Independencia, explicado y confrontado con las bases doctrinales con las que se fundó el 28 de julio de 1821.

\section{Los primeros cincuenta años: hibridación y centralización (1825-1872)}

Como toda narrativa que da cuenta de la realidad, la lectura de Neira (2013) sobre el olvidado debate republicano contiene parte de verdad y parte de interpretación, inclusive, de sublimación. Es posible, por eso, que tras

1 En este ensayo defendemos la tesis de que el docenio 1980-1992 representó la Primera República Democrática de nuestra historia independiente. Los argumentos serán expuestos en las siguientes páginas. 
esta encontremos las poderosas causas que impidieron que aquel debate tuviese lugar o que las polémicas constitucionalistas de los primeros tiempos no hayan calado al punto de cimentarse en una sólida tradición democrático-institucional.

Se ha dicho hasta la saciedad que, a diferencia de Francia, en el Perú la revolución política no fue al mismo tiempo social, lo que nos enfrentó a la paradoja de una flamante república liberal, rigiendo los destinos políticos de una sociedad del Antiguo Régimen. Es posible que con la derrota de Túpac Amaru en 1781 haya comenzado a construirse la explicación de nuestra singularidad. En 1781, perdió la élite andina, principalmente la inca, y en 1814, lo que quedaba de ella volvió a sucumbir después de la derrota de los hermanos Angulo y de Mateo Pumacahua.

De allí que Alberto Flores Galindo (1993) haya sostenido que la antigua república de indios, consagrada por su majestad española, careció de una clase dirigente que la organizase y representase el día que se produjo o debió producirse el debate sobre la república que queríamos ser. La abolición bolivariana de los curacazgos terminó el proceso de desactivación de las élites andinas que iniciase la represión colonial en 1781.

Por eso, no tuvimos una asamblea como la Convención Francesa o la Americana de Filadelfia, la que, en genuina representación del pueblo, culminó la redacción de su primera y única constitución el 7 de junio de 1776 y, ya con esta aprobada, procedió a independizarse de la corona británica el 4 de julio del mismo año. Siempre podrá señalarse que los Estados Unidos mantuvieron la institución de la esclavitud hasta la guerra de Secesión y la segregación de los afroamericanos hasta pasada la primera mitad del siglo xx. Esto es positivamente cierto, tanto como que desde 1776 Estados Unidos inició un proceso continuo de fortalecimiento de sus instituciones republicanas, el que prosigue hasta hoy. Este no es nuestro caso.

\subsection{El devenir de una compleja hibridación corporativo-republicana: la política peruana hasta 1872}

La premisa sostenida en los párrafos anteriores bien podría rebatirse. De hecho, en los procesos electorales del siglo xIx, hasta el reglamento electoral de 1896, sancionado durante el segundo gobierno de Nicolás de Piérola, y de acuerdo con la provincia o la oportunidad, tanto indígenas como la tropa de decenas de caudillos militares que pululaban por el país votaban en las elecciones provinciales mediante un complejo sistema electoral indirecto. Seguidamente, se conformaban asambleas regionales que elegían al presidente y congresistas, no sin la intermediación del Congreso o del Poder Judicial como instancias decisivas para la resolución de controversias, lo que debe entenderse como la arbitral facultad para inclinar la balanza en favor del caudillo militar vencedor de la última de tantas guerras civiles, que entonces llamábamos revoluciones (Aljovín, 2005).

Y puede ser por eso que hasta hoy, en nuestra cultura política contemporánea, solemos confundir democracia con plebiscitarismo y pensamos que si la mayoría avala un golpe de Estado en una encuesta de opinión, este resulta legítimo. Aquello se pensaba entonces y se piensa ahora, pero, en esos tiempos, la virtual universalidad del sufragio avivaba el enmarañado entrecruzamiento de las tradiciones corporativa y liberal. De esta manera, el voto cantado de la tropa en favor de su general, de la clientela política urbana en favor del prefecto o algún potentado, del peón por su hacendado e inclusive del comunero por alguno de los últimos caciques, reproducían, a la vez que revestían con ropaje republicano, la vieja relación de sujeción de hombre a hombre, propio de la sociedad colonial, en la que las personas se ordenaban jerárquicamente sobre la base de su linaje y nacimiento. Además, se trata de una sociedad peruana que ingresa a un avanzado proceso de feudalización por la cada vez más escasa presencia del Estado, que se ve así obligado a apelar a las viejas relaciones corporativas del régimen colonial para elegir a sus autoridades políticas provincianas.

Son estos elementos los que nos llevan a defender la tesis de una hibridación corporativo-republicana durante el siglo xIx; a pesar de que Carmen Mc Evoy, en La utopía republicana, nos ofrece una visión más optimista y sostiene que el republicanismo fue adoptado en todas las esferas políticas del Perú decimonónico como elemento legitimador de las autoridades políticas. La tesis no deja de ser correcta si observamos que, como señala Cristóbal Aljovín (2005), los caudillos vencedores de las guerras civiles, luego de convertirse en presidentes provisorios, convocaban a elecciones que, tautológicamente, los convertían en presidentes constitucionales. Sin embargo, no puede restársele a la idea, el sustrato sociopolítico de los procesos electorales que movilizaban, a la antigua manera corporativa, a un electorado cuyo voto distaba de ser individualista, liberal o democrático (Mc Evoy, 1997a).

En "El legado castillista", Mc Evoy (1996) le añade a este complejo esquema la tesis de la fundación de una 
particular cultura política peruana por Ramón Castilla, durante el periodo en el que el célebre militar prevaleció en el gobierno (1845-1861, incluimos el intervalo de Echenique 1851-1854). Sucintamente, la historiadora sostiene que la azarosa trayectoria del libertador de los esclavos le permitió tender redes clientelares por todo el país, cuya fidelidad mantuvo mientras permaneció en el poder y las ganancias de la venta del guano en Europa le permitieron al Estado financiarles generosas prodigalidades a dichas redes.

En tal sentido, Castilla logró pacificar al país comprando a los grupos de influencia más poderosos de las diferentes regiones del interior, como a los hacendados de la costa norte, pagándoles un alto precio por sus esclavos al decretarse en 1854 su manumisión; a la élite limeña, liquidando la deuda de la Independencia, cuya consolidación devino en escándalo en tiempos de Echenique, cuando misteriosamente el monto que se debía abonar se elevó de cuatro a veintitrés millones de pesos. También se habrían beneficiado los gamonales serranos, con quienes básicamente se prolongó el orden colonial, gracias a la privatización del cobro del tributo indígena cuando Castilla decidió eximir a estos de dicha cotización.

Para Mc Evoy (1996), con Castilla se llevó a cabo un primer intento de centralización estatal frente a lo que no había sido otra cosa más que una anarquía militar en la que los diferentes poderes y fuerzas centrífugas del país, cada tanto, revestían de un halo de legitimidad, mediante el voto, al último caudillo vencedor de la reciente guerra civil, ungido con el título de presidente provisorio. En cambio, con el vencedor de la batalla de La Palma, el Estado, por medio del gobierno establecido en Lima, la capital, pudo controlar al país y dotar las políticas públicas de alguna coherencia. Esta suerte de pacificación tras un largo periodo de anarquía militar, pudo lograrse, lo hemos dicho, con la repartición más o menos equitativa de las riquezas guaneras.

En el plano ideológico, la legitimidad del gobierno de Ramón Castilla se consolidó con la doctrina del bien común planteada por el sacerdote Bartolomé Herrera, ideólogo del castillismo, quien desarrolló una singular tesis que vinculó la teoría monárquica del derecho divino con el planteamiento positivista de la soberanía de la inteligencia. De este modo, al gobernante se le revestía de un aura de legitimidad que convertía a cualquier opositor en antisistémico y, por lo tanto, en objeto de represión (Mc Evoy, 1996).

Sin embargo, a nosotros nos suena a mucho considerar a Ramón Castilla el fundador de una cultura política peruana basada en una relación patrimonialistaclientelar entre Lima y provincias. De hecho, el concepto de patrimonialismo amerita unas líneas, pues define la relación del funcionario con el cargo o función pública que ejerce, la que se asume como el bien propio de quien lo ostenta. De este modo, obtiene beneficios materiales más allá de la remuneración y, al mismo tiempo, consolida o tiende una red más o menos fiel de paniaguados, también favorecidos por el poder que el Estado ha depositado en aquel y por el dinero que directa o indirectamente administra.

A nosotros no nos parece que Castilla haya fundado una cultura política específica, a fuer de administrar, con notable habilidad, un proceso de hibridación sociopolítica que se inicia con la Independencia y se caracteriza por la existencia de redes extensas y complejas, semiindependientes unas de otras, que Castilla logra controlar desde Lima, es decir centralizar, gracias a las ganancias del guano. Más allá de la coyuntural centralización llevada a cabo por el célebre caudillo, el clientelismo, el patrimonialismo y la fuerte presencia de elementos corporativistas en la sociedad y política peruanas del siglo XIX anteceden y sobreviven al castillismo, tanto, que, bajo formas y dinámicas contemporáneas, pueden observarse en la actualidad.

Castilla centraliza, une los cuerpos sociales alrededor del Estado, posiciona temporalmente a Lima, pero dista de fundar una cultura política, al punto de que la red que construyese se desbaratará poco después, en cuanto se hizo presente la crisis económica a mediados de la década de 1860 (Mc Evoy, 1997b). Persistieron, sí, el clientelismo, el corporativismo y el patrimonialismo como formas políticas mediante las cuales se hibridan la herencia colonial y el proyecto republicano de los padres fundadores.

\section{La nueva hibridación y el fracaso de la Primera República Democrática: fujimorismo y patrimonialismo}

El proyecto republicano de Manuel Pardo apostó por el ciudadano virtuoso y educado en el ejercicio de la función pública, en reemplazo del pragmático funcionario patrimonialista, que disfrutaba con ventaja los beneficios del cargo como antes lo hicieron sus pares coloniales (Mc Evoy, 1997b). Lo cierto es que la crisis económica, agravada considerablemente por la gran depresión mundial 
de 1873 y la declaración chilena de la Guerra del Pacífico en 1879 , hicieron estallar el primer emprendimiento civilista y generaron una cesura que nos llevó directo y de nuevo a los caudillos con el empoderamiento de Andrés Cáceres, vencedor de Tarapacá, en la presidencia de la República, en el periodo de posguerra.

La notoria interrupción de lo que pudo significar la paulatina construcción de una institucionalidad democrática, luego de seis décadas casi continuas de militarismo, nos regresa a la tesis de las diversas fundaciones republicanas, tanto como de las alternancias entre autoritarismos y constitucionalismos, además de las fusiones entre ambos, que recurrentemente hemos experimentado.

Es por ello que vamos a aventurarnos en una lectura comparada del periodo que acabamos de analizar,
El pacto entre viejos enemigos políticos le abrió el paso a un periodo de partidarización de la política peruana: no solo el APRA volvió a la legalidad, también lo hizo el Partido Comunista, mientras que poco después aparecieron otros nuevos, como Acción Popular y Democracia Cristiana. las primeras que pueden considerarse libres y democráticas desde 1931. Sin embargo, la sombra del militarismo se proyectó de nuevo sobre el Perú con el veto militar a la candidatura de Víctor Raúl Haya de la Torre y el golpe militar del 17 de julio de 1962, cuya finalidad fue evitar su eventual nominación como presidente de la República por el Congreso, o la del exdictador Manuel Odría. De este modo, el sector progresista de las Fuerzas Armadas evidenció su preferencia por la candidatura de Fernando Belaúnde y preparó las condiciones para su triunfo en las elecciones presidenciales que convocó para 1963 (Parodi, 2015).

Lo cierto es que la acelerada transformación social del país, precipitada por la vertiginosa transición demográfica, y la masiva migración del campo a la ciudad fueron desafíos difíciles de afrontar para Belaúnde, ya investido presidente. La situación se agravó puesto que los sectores más con el que se inaugura a finales de docenio militar de Velasco-Morales Bermúdez, desde la entrada en vigencia de la Constitución Política de 1979 hasta los tiempos actuales. ¿Cuán institucional y moderna es nuestra república? ¿Cuáles son los elementos tradicionales que remiten a antiguas estructuras sociopolíticas y prácticas coloniales? ¿Cómo estos elementos se relacionan con el mundo y el Perú globales? ¿Remite la comparación que nos planteamos a la confrontación entre los elementos de una realidad pasada y una futura que establecen vasos comunicantes entre sí? o, más bien, ¿es apenas el discurso, la narración, la que le otorga coherencia a un diálogo diacrónico que no se sostiene fuera del relato?

\subsection{La Primera República Democrática}

Un año precursor de la democracia en el Perú es 1956: marcó el entendimiento entre el sector más liberal de la oligarquía dominante y el APRA —el partido más grande y estructurado del Perú-, que de esta manera dejaba atrás veinticinco años de persecución casi ininterrumpida. El pacto entre viejos enemigos políticos le abrió el paso a un periodo de partidarización de la política peruana: no solo el APRA volvió a la legalidad, también lo hizo el Partido Comunista, mientras que poco después aparecieron otros nuevos, como Acción Popular y Democracia Cristiana, lideradas respectivamente por Fernando Belaúnde Terry y Héctor Cornejo Chávez.

Este retorno al constitucionalismo explica las disputadas elecciones de 1962 con seis candidatos presidenciales: conservadores de la oligarquía lograron defender sus posiciones en el Congreso a través de su alianza con el APRA, la que les otorgó la mayoría absoluta y les permitió bloquear reformas impostergables, como la agraria y la tributaria, que hubiesen permitido atender las necesidades más urgentes de un país en franca ebullición.

Aunque las siguientes elecciones estaban programadas para 1969, los militares decidieron no esperar y aprovecharon el escándalo de la página once para perpetrar un golpe de Estado el 3 de octubre de 1968. Desde entonces, aplicaron ellos mismos un programa radical que tuvo en la reforma agraria la política más emblemática del proceso que se extendió hasta 1980. Con esta, se derrumbó el poder oligárquico incapaz de mantener en pie prerrogativas señoriales que se remontaban al periodo colonial y se gestó una nueva sociedad sin sus antiguas fracturas socioculturales, pero con otras, igual de profundas, que derivaron de la crisis económica y la incapacidad del Estado para satisfacer la demanda de servicios y de empleo de millones de nuevos ciudadanos asentados en la periferia de las grandes ciudades.

Es en este contexto en el que, asfixiado por la intensidad de la crisis y masivas protestas sociales, el Gobierno Revolucionario de las Fuerzas Armadas inicia un proceso de transición democrática a través de la convocatoria a una Asamblea Constituyente que se instaló el 28 de julio de 1978. Los resultados de dichos comicios le ofrecieron al país un panorama particular, pues por primera vez en su historia, el espectro político se dividía en los tres tercios tradicionales: la derecha, representada por 
el Partido Popular Cristiano (PPC); el centro o centro-izquierda, representado por el APRA; y la izquierda comunista, dividida en varias agrupaciones que juntas alcanzaron treinta y cuatro de las cien curules. La otra conclusión evidente que nos dejó dicha elección es que, también por primera vez en la historia del Perú, la mayor parte de los sectores de la sociedad peruana canalizaron su vínculo con el Estado a través de partidos políticos.

La Asamblea Constituyente, que presidió Víctor Raúl Haya de la Torre, consolidó el proceso de democratización del país establecido a través de los partidos al otorgarle, en el texto de la Constitución de 1979, el voto a los analfabetos, que por entonces constituían aún alrededor del $20 \%$ de la población. De esta manera, se fundó la Primera República Democrática de la historia del Perú, cuyos basamentos fueron la irrestricta igualdad ante la ley, la universalidad del sufragio y los partidos políticos, en tanto eran los vasos comunicantes entre la sociedad y el Estado.

El mismo esquema se repitió en las elecciones generales de 1980 y 1985 . En la primera, las preferencias electorales se trasladaron hacia la centro-derecha de Acción Popular, cuyo candidato, Fernando Belaúnde ganó en primera vuelta con el $47 \%$ de los votos. Este alcanzó la mayoría parlamentaria aliándose con el PPC de Luis Bedoya Reyes. Sin embargo, la centro-izquierda y la izquierda se mantuvieron fuertes con el $26 \%$ alcanzado por el candidato aprista Armando Villanueva del Campo y por el $15 \%$ que sumaron las diferentes izquierdas marxistas.

La división tripartita del espectro político se repitió una vez más en las elecciones de 1985, aunque en esta oportunidad, ante el agravamiento de la crisis durante el quinquenio acciopepecista, el electorado se inclinó por la izquierda. Fue así que resultó electo el joven candidato del APRA, Alan García Pérez, con el 53\% de los votos válidos, frente al $24 \%$ de Izquierda Unida, la que finalmente alcanzó una candidatura de consenso alrededor de la carismática figura de Alfonso Barrantes Lingán. Esta vez, el espectro de la derecha se redujo al $18 \%$ de las preferencias, con el $11 \%$ obtenido por Luis Bedoya Reyes, del Partido Popular Cristiano, sumado al $7 \%$ de Javier Alva Orlandini, candidato de la oficialista Acción Popular.

Este repaso de los resultados de tres procesos electorales, 1978, 1980 y 1985, nos sirve para sustentar nuestra tesis de que el 28 de julio de 1980, cuando Fernando Belaúnde asumió la presidencia del Perú, iniciamos el periodo que hemos llamado Primera República Democrática. La he llamado así, en primer lugar, para distinguirla del periodo denominado República Aristocrática, que abarcó el periodo 1895-1919 y que, de acuerdo con las tesis de Pedro Planas, implementó un constitucionalismo restringido o censitario en el que solo tenía derecho a elegir y ser elegido una fracción minúscula de la población compuesta por varones, alfabetos y contribuyentes.

Sin embargo, Planas observa también que, por regla general, el liberalismo político comienza con regímenes censitarios, los que luego transitan a repúblicas democráticas, una vez que, mediante la acción política y sindical, las masas conquistan los derechos al sufragio y laborales. Para Planas, el advenimiento de Leguía en 1919 privó al Perú de dicha transición que sí experimentaron muchos otros países, incluso de la región, como es el caso de Chile. Al contrario, nosotros incubamos el militarismo institucional como respuesta vertical a la irrupción de las masas en la política (Planas, 1994).

En esa misma línea, hemos situado el periodo 19561968 como el antecedente más directo de la Primera República Democrática, el que, sin embargo, fue interrumpido por el docenio militar de 1968 a 1980, en el cual, de manera paradójica, se generaron las condiciones para iniciar un periodo de irrestrictas libertades civiles y vigencia del constitucionalismo, como el que se inauguró el 28 de julio de 1980 y rigió hasta el 5 de abril de 1992, cuando un autogolpe de Estado, perpetrado por el entonces presidente Alberto Fujimori, echó por tierra el proceso de democratización política iniciado doce años antes.

\subsection{Las crisis dela Primera República Democrática yel clientelismo fujimorista}

Solo 160 años después de fundado, el Perú independiente alcanzó la Primera República Democrática mediante la Constitución de 1979, que universalizó todos los derechos ciudadanos, que previamente alcanzaron a la mujer en 1956 y luego al analfabeto desde 1980. Sin embargo, apenas doce años después, estalló en pedazos cuando el presidente Alberto Fujimori decidió convertirse en dictador y ordenó a las Fuerzas Armadas cerrar el parlamento e intervenir las más importantes instituciones del Estado, como las judiciales y electorales. Al mismo tiempo, arreció en una potente campaña de desprestigio en contra de los que denominó "partidos tradicionales", ciñéndolos en una crisis de institucionalidad y legitimidad de la que no se recuperan hasta hoy.

En realidad, la coyuntura que dio la oportunidad a Fujimori para quebrar una institucionalidad gestada 
librando todo tipo de dificultades desde la fundación de la República se debió a la conjunción de una serie de aspectos. El primero fue la crisis de la deuda externa que vivió América Latina desde 1975 hasta los inicios de la década de 1990. En 1973, la Organización de Países Exportadores de Petróleo (OPEP) congeló el precio del petróleo y el barril cuadruplicó su precio. Esta situación generó una galopante inflación de los precios y de las tasas de interés bancario. Al mismo tiempo, los dólares de los países importadores de petróleo triangularon hacia los países productores y de allí, al sistema bancario.

En simultáneo, la crisis sorprendió a los países en vías de desarrollo que, bajo diversas puestas en escena, venían aplicando las políticas cepalinas de desarrollo industrial por sustitución de importaciones sobre la base de un crédito bancario cuyas condiciones de pago se tornaron leoninas debido a la crisis. De esta manera, desde los primeros años de la década de 1980, importantes países de la región, como México, señalaron que no poseían la liquidez necesaria para abonar los intereses de las deudas y obligaciones adquiridas.

En el Perú, la situación económica se agravaba por la radicalidad de las reformas velasquistas que quedaron a medio hacer y con las que se debió convivir en tiempos en los que el Fondo Monetario Internacional (FMI) apuntaba más bien a un desarrollo desde la apertura comercial, antes que a través de la industrialización por sustitución de importaciones (ISI). Sin revertir por completo las reformas velasquistas, la segunda gestión gubernamental de Fernando Belaúnde Terry se ciñó al plan de pagos del FMI, lo que disminuyó severamente la posibilidad de aumentar el gasto público. En todo caso, ni la deuda ni la inflación ni la crisis menguaron.

A su turno, desde 1985, el joven presidente aprista, Alan García Pérez, desafió al sistema financiero internacional lanzando la unilateral tesis de asignar al pago de la deuda externa el $10 \%$ de regalías estatales obtenidas del rubro de exportaciones. Al mismo tiempo, lanzó una agresiva política de reactivación productiva ofreciendo a los principales capitalistas del país un dólar más barato si se utilizaba para importar insumos industriales y potenciar la reactivación en marcha.

El resultado de esta política, que vino acompañada, además, de un significativo aumento del gasto público, fue la fuga de capitales ante la escasa fiscalización de los dólares transferidos al sector privado, con la supuesta finalidad de reinvertirse en el país. De esta manera, el 28 de julio de 1987, con las reservas fiscales en negativo, García anunció la nacionalización del sistema financiero y el congelamiento de los ahorros en dólares: la reactivación productiva había fracasado, la inflación y devaluación de la moneda se dispararon, y la crisis económica alcanzó ribetes nunca antes vistos en el siglo xx.

Mientras que en 1980 se iniciaba la Primera República Democrática y se gestaba la crisis de la deuda externa a escala mundial, el Perú mostraba a sí mismo su nuevo perfil demográfico. Había finalmente terminado el coloniaje, el país de señores blancos y siervos indígenas se había perdido en la historia, y el país ochentero, literalmente, migraba del campo a la ciudad e invertía sus tendencias demográficas. Por primera vez, un país pensado por su vieja oligarquía dominante como dividido por un abismo entre las ciudades de la costa y las haciendas de la sierra rural unía sus partes. También, por primera vez, millones de peruanos se asentaban en la periferia de las ciudades litorales y obtenían el derecho a elegir y ser elegidos gracias a la Constitución de 1979.

En tanto, el Perú se tardó 160 años en instaurar un sistema político democrático, la sociedad peruana apenas comenzaba a afianzar un proceso de urbanización en el que absolutamente todo hacía falta: la vivienda, el asfalto, la luz, el saneamiento, el agua y el desagüe, la salud y la educación. Así, paradójicamente, la conquista de los derechos civiles, que costó décadas de lucha a las generaciones pasadas, era en realidad la última de las preocupaciones de una ciudadanía nueva, pauperizada, que luchaba afanosamente por encontrar un medio de vida, el que obtuvo principalmente por medio del comercio informal y sin la ayuda de nadie o de casi nadie. La brecha entre el Perú político y el social parecía una vez más insalvable. Aunque por razones distintas a las planteadas por Flores Galindo, también la Primera República Democrática carecía de ciudadanos que creyesen en ella o se la tomasen en serio (Flores Galindo, 1993).

Como si la crisis económica y el divorcio inicial entre el Perú político y el emergente no hubiesen sido suficientes, el terrorismo comunista de Sendero Luminoso y el Movimiento Revolucionario Túpac Amaru (MRTA) liquidaron cualquier posibilidad de reconectar al Estado y la clase política con la sociedad y sus urgentes necesidades. De esta manera, un país que año a año acrecentaba su déficit fiscal se vio sacudido por la brutal destrucción de su ya precaria infraestructura como consecuencia de centenas de atentados dinamiteros, los que, además, generaron una situación de inseguridad que ahuyentó las inversiones extranjeras y nacionales, de por sí timoratas de asentarse en el país debido a las nacionalizaciones llevadas a cabo por el precedente régimen militar de los generales Velasco y Morales Bermúdez. 
Así las cosas, la Primera República Democrática no solo nació tarde, sino con una condena a muerte a cuestas, lo que remite a lo que alguna vez se preguntaron Enrique Bernales y Hugo Neira: ¿qué hubiese pasado si a Haya de la Torre se le hubiese dado la oportunidad de instaurar la modernidad política en el Perú medio siglo antes? (Bernales, 2017; Parodi, 2013). La oligarquía y las Fuerzas Armadas lo impidieron repetida y entusiastamente, a tal punto que, al nacer la Primera República Democrática, esta ya no se correspondía con la sociedad a la que pretendía representar y, como todo lo que sucede en el Perú es sui géneris, un outsider de origen japonés, Alberto Fujimori, pronto se convertiría en su sepulturero.

Las pompas fúnebres de la República Democrática fueron preparadas minuciosamente por el personaje más brillante y siniestro del régimen autoritario en ciernes: el asesor de inteligencia Vladimiro Montesinos. Sin negar la dureza de la situación heredada del primero gobierno aprista, el asesor generó meticulosamente una atmósfera golpista basada en los supuestos de que los partidos políticos de oposición, que constituían la mayoría en el Congreso, boicoteaban al Ejecutivo en tiempos en los que Sendero Luminoso estaba a punto de derrotar al Estado peruano para instaurar una dictadura totalitaria de corte maoísta en el Perú.

La realidad, sin embargo, era distinta, el gabinete Hurtado Miller recibió el respaldo de un Congreso que, aunque fraccionado, era consciente de la situación, mientras que las rondas campesinas expulsaban a Sendero del campo y el Grupo Especial de Inteligencia de la Policía (GEIN), formado en 1989, se encontraba muy cerca de capturar y descabezar a la cúpula senderista y, con ello, desactivar a este sanguinario movimiento. Los hechos demostraron esta hipótesis: apenas cinco meses después el autogolpe del 5 de abril, el 12 de septiembre del mismo año, el GEIN realizó la captura del siglo sin que ni Fujimori ni su inefable asesor de inteligencia estuviesen al tanto del operativo, cuya autoría, sin embargo, se adjudicaron de inmediato.

Más allá de eso, el 5 de abril de 1992 es una fecha crucial en la historia republicana del Perú, pues comenzó a aplicarse un potente proyecto del que emergió la cultura política peruana del siglo xxl, que se gesta de la sinergia entre dicho proyecto, una serie de prácticas políticas del pasado que el siglo xx no fue capaz de erradicar y los enormes cambios en la configuración mundial tras el fin de la Guerra Fría, la caída del bloque socialista, el inicio del proceso de globalización mundial, la difusión de las TIC, el Consenso de Washington, el plan Brady, etcétera.
Lo primero que debemos resaltar del proyecto fujimorista fue su carácter autoritario, que implicó la cooptación de, básicamente, todas las instituciones del Estado, además del control de los medios de comunicación e inclusive de los organismos electorales. La contraparte, lo hemos dicho, consistió en la agresiva campaña de desprestigio en contra de los partidos políticos llamados "tradicionales", incluida la demolición mediática de cualquier líder que pudiese ser o representar una amenaza para el régimen.

Lo segundo, sin lo cual no aplica lo anterior, fue la instauración de una agresiva política caudillista-clientelar centralizada desde el Ministerio de la Presidencia, creado con la finalidad de asociar con la persona del presidente, prácticamente, todas las obras públicas de infraestructura, educación, salud y saneamiento llevadas a cabo por el Estado. A esta, se sumaron las políticas directamente asistenciales, como los comedores populares, clubes de madres y programas del vaso de leche que el gobierno central arrebató a los municipios para pasar a administrarlos directamente. El toque ideológico de estas políticas lo aportó una serie de programas televisivos y diarios llamados "chichas", que recrearon un efecto de realidad con la intención de generar una sensación de inclusión social, asociando a los sectores emergentes con el proyecto político en curso.

Así, se fue gestando el imaginario que legitimaba el perfil autoritario de Alberto Fujimori presentándolo como un presidente preocupado por las necesidades primarias de los sectores populares, pauperizados por la crisis y la transición demográfica, y capaz de resolver sus problemas más urgentes. Sin el partido político como intermediario, la relación con el Estado se verticalizó y se estableció un vínculo directo entre la población y los representantes del régimen, responsabilidad que, principalmente en provincias, recayó sobre líderes emergentes del sector informal.

De esta manera, se activaron o reactivaron las redes clientelares que marcaron la relación poblador-Estado en el siglo xIx y que se prolongaron durante el siglo $x x$, solo parcialmente interrumpidas cuando cincuenta años de esfuerzos del APRA —al que se sumaron luego otros partidos como Acción Popular, el PPC y aquellas izquierdas que zanjaron con la violencia política- lograron instituir la precaria Primera República Democrática el 28 de julio de 1980. Entonces, se apostó por promover una relación ciudadanía-Estado canalizada a través de organizaciones políticas formales, en contraposición a las tradicionales redes clientelares alrededor de principales provincianos o servidores 
públicos con capacidad de redistribuir recursos del Estado entre sus allegados.

\section{A manera de conclusión: las redes están solas otra vez}

Como hemos visto en "El legado castillista" (Mc Evoy, 1996), con el dinero del guano, Ramón Castilla logró controlar las diversas y díscolas redes clientelares provinciales. Favorecidas por la consolidación de la deuda externa, la abolición de la esclavitud e importación de trabajadores chinos y la privatización del tributo indígena, estas se adhirieron al esquema centralizador y patrimonialista del hábil militar tarapaqueño. Sin embargo, durante la segunda mitad de la década de 1860, la paz castillista entró en crisis debido a la discutible habilidad de sus sucesores y al hecho insoslayable de que los recursos guaneros empezaron a menguar.

Dentro de esta lógica, el contrato Dreyfus no habría sido sino el intento de la administración Balta-Piérola de obtener recursos frescos para mantener contentas a las élites provinciales $y$, de tal manera, prolongar la paz social bajo la fórmula que desde 1845 empezase a aplicar Ramón Castilla (Mc Evoy, 1996). Ciertamente, una sola causa no explica una compleja transacción económica que se realizó también desde una mirada desarrollista que la asoció a la obtención de ingentes préstamos para solventar dos espectaculares proyectos ferroviarios. Con estos, se buscaba acceder al progreso y a los recursos mineros del centro y laneros del sur para potenciar su exportación y compensar la disminución de los ingresos provenientes del guano (Contreras y Cueto, 2013, pp. 148-155).

Lo cierto es que el uso irresponsable de los recursos obtenidos por medio del referido contrato y la crisis mundial de 1873 propiciaron el colapso del precario centralismo estatal establecido por Ramón Castilla y del tardío intento civilista de erigir un gobierno bajo formas constitucionales y republicanas forjadas sobre la base del ciudadano virtuoso, moderno y educado. Como colofón, la Guerra del Pacífico (1879-1883) forzó la independización de las viejas redes provinciales del centralismo limeño, lo que, a su vez, sentó las condiciones para la consolidación del poder de los gamonales serranos durante la subsecuente República Aristocrática (Burga y Flores Galindo, 1987, primera parte, cap. 2, y segunda parte, cap. 2).
Casi de 120 años después de la Guerra del Pacífico, el país recuperó la democracia luego de la huida del dictador Fujimori en las circunstancias más penosas que le ha tocado vivir al Perú independiente; pero los que no volvieron más fueron los partidos políticos. En el 2001, resultó electo Alejandro Toledo gracias al esfuerzo de una maquinaria electoral -Perú Posible- que al momento de escribir estas líneas, prácticamente, ya no existe. En el 2002, Toledo promulgó una bienintencionada, pero temeraria, ley de regionalización que no tomó en cuenta la ausencia de partidos políticos sólidos y de escala nacional que pudiesen competir y ofrecer cuadros más o menos competentes para conducir veinticuatro flamantes gobiernos regionales.

Sin su principal protagonista, el partido, la república regionalizada que imaginó Toledo devino en la vertiginosa refeudalización política de la nación, expresada en cientos de movimientos regionales, provinciales y hasta distritales que compiten los unos contra los otros por copar cargos públicos $y$, de esta manera, favorecerse de todos sus beneficios: recursos públicos transferidos del gobierno central, cánones o regalías mineras, pródigas concesiones, consultorías otorgadas a paniaguados, etcétera.

De suerte que, ad portas del bicentenario, el país ha virado en sentido inverso a las agujas del reloj de la historia y reproduce, potenciado con infraestructura y tecnologías desconocidas en el siglo xIx, las viejas redes clientelares que desde hace 194 años nos demuestran que hasta ahora no hemos sido capaces de encontrar el camino hacia una república democrática de ciudadanos iguales ante la ley, que encuentren en la virtud cívica y el servicio a la comunidad, la razón del ejercicio de la gestión pública, más allá de que estuvimos cerca de instaurarla entre los años 1980 y 1992. Perdimos esta república debido a bombazos, una crisis galopante, la maquiavélica nocturnidad de un sombrío asesor de inteligencia y la inescrupulosidad de un outsider dispuesto a echar por tierra el Estado de derecho con tal de perpetuarse en el poder.

Parte de este proyecto autoritario consistió en el fortalecimiento de alianzas de intereses entretejidas por redes clientelares, sostenidas a veces por bandas criminales dedicadas a actividades ilícitas como el narcotráfico, la minería ilegal, el sicariato etcétera. Estas han revivido, con ropaje contemporáneo, a los antiguos señores provinciales que, al igual que en siglo xIx, hoy encuentran en los rituales democráticos apenas una formalidad por cumplir cada cierto tiempo cuando se va a votar. 
A esto, le llamamos "hibridación republicana", formato que hasta el día de hoy suplanta a la república democrática y constitucional que deberíamos ser, tanto como la suplantó en las primeras décadas republicanas, como nos los relata Cristóbal Aljovín en su esclarecedor "Votos y bayonetas: Perú 1825-1851" (2005). Mientras tanto, en un lejano pueblo cercano a Cerro de Pasco, el taimado juez Montenegro se sigue ganando todos los corderos finos que se sortearon en una tarde fría y con mucha lluvia, pero con poquísimos ciudadanos². En simultáneo, los pobladores del Perú esperan, con aburrida indiferencia, el inicio de los festejos del bicentenario de una república que sigue sin saber cómo convertirse en tal.

\section{Referencias}

A suovín, C. (2005). Votos y bayonetas: Perú 1825-1851. Revista Elecciones, (5).

ANDERSON, B. (1997). Comunidades imaginadas. Reflexiones sobre el origen y la difusión del nacionalismo. México: Fondo de Cultura Económica.

Beto A SABER (16 de mayo del 2017). Entrevista a Enrique [archivo de video]. Recuperado de http://www.atv.pe/ actualidad/enrique-bernales-triste-descubrir-quien-votaste-criminal-329999?ref=nota-rel\&app=play

BuRga, M., y Flores Galindo, A. (1987). Apogeo y crisis de la República Aristocrática (oligarquía, aprismo y comunismo en el Perú 1895-1932). Lima: Ediciones Rikchay Perú.

Contreras, C., y Cueto, M. (2013). Historia del Perú contemporáneo (5.a ed.). Lima: Instituto de Estudios Peruanos, Fondo Editorial de la Pontificia Universidad Católica del Perú, Universidad del Pacífico.

DARGeNt, E. (2009). Demócratas precarios: élites y debilidad democrática en el Perú y América Latina. Lima: Instituto de Estudios Peruanos.

FLoRES GALINDO. A. (1987). Buscando un Inca. Lima: Instituto de Apoyo Agrario.

HobsBawn, E. (1991). Nacionales y nacionalismo desde 1870. Barcelona: Crítica.

KLARén. P. (2014). Nación y sociedad en la historia del Perú. Lima: Instituto de Estudios Peruanos.

LóPEZ, S. (1997). Ciudadanos reales e imaginarios: concepciones, desarrollo y mapas de la ciudadanía en el Perú. Lima: Instituto de Diálogo y Propuestas.

Mc Evor, C. (1996). El legado castillista. Histórica, XX(2).

Mc. Evor. C. (1997a). Utopía republicana. Ideales y realidades en la formación de la cultura política peruana. Lima: Pontificia Universidad Católica del Perú.

Mc. Evoy, C. (1997b). La experiencia republicana: política peruana, 1871-1878. En H. Sábato (coord.), Ciudadanía política y formación de las naciones. México: Fondo de Cultura Económica.

NeIRA, H. (2009). Perú siglos XVI-XIX. Ensayos de relectura herética. Lima: Universidad Inca Garcilaso de la Vega.

NeIRA, H. (2013). ¿Qué es nación? Lima: Universidad de San Martín de Porres.

PARODI, D. (17 de septiembre del 2015). Haya y Prado. Caretas (2403).

PARODI, D. (15 de junio del 2013). El APRA de Hugo Neira [mensaje en blog Palabras Esdrújulas]. Recuperado de http:// blog.pucp.edu.pe/blog/daupare/2013/06/15/el-apra-de-hugo-neira/

PlanAs, P. (1994). La república autocrática. Lima: Fundación Friedrich Ebert.

2 Refiere la novela Redoble por Rancas, de Manuel Scorza. 